FACTORS INFLUENCING MOVEMENTS OF PTERONARCYS NYMPHS IN PACIFIC CREEK, GRAND TETON NATIONAL PARK, WYOMING

\author{
Jerry Freilich \\ Department of Entomology \\ University of Georgia \\ Athens
}

\title{
Introduction
}

Controversy continues over the relative importance of resource limitation and intraspecific competition in stream ecosystems (Grossman et al 1982, Hart 1983). The chief trouble is separating densityindependent effects (e.g., Knight and Gaufin 1963) from effects that are density-dependent (i.e., biological) (Peckarsky 1979).

Movements of marked individuals can reveal fine detail about intraspecific competition or effects of environmental heterogeneity. My research uses individually narked stoneflies (Pteronarcys californica) to study movement patterns. Pteronarcys was chosen because it is large enough to tag and can be caught by electroshocking. The work has 2 parts: a descriptive study of stonefly movements, and a series of manipulations to probe factors affecting them.

The descriptive study was conducted in 1987: (1) to determine feasibility of catching and marking large numbers of stoneflies; (2) to obtain life history data (sex, size, phenology); (3) to find out the size of Pteronarcys home ranges; and (4) to discover maximum distance and maximum rate the stoneflies can move. Purposes (3) and (4) were intended to guide formulation of the manipulation study by providing an estimate for sample and quadrat sizes.

The manipulation study, (July-November 1988), was a randomized block ANOVA design. Food and stonefly density were manipulated in $4 \mathrm{~m}^{2}$ quadrats in Pacific Creek. Purposes of the manipulation were: (1) to see if stoneflies use available habitat differentially; (2) to discover the relative importance of food availability in explaining stonefly distribution; (3) to test for intraspecific interactions as determinants of movement; (4) to look for interactions between food and intraspecific factors.

I present here some results from 1987 and summarize data from 1988 (only now beginning to be analyzed).

Methods: Field Season of 1987

The work was conducted in a $360 \mathrm{~m}$ long side channel of Pacific Creek in 
Grand Teton National Park, WY. The area is a gravel bar with sparse riparian vegetation (mainly Salix). Nearby forest of Pinus contorta is set back from the stream edge by $\approx 70 \mathrm{~m}$.

The study reach included 2 large pools and 3 fast riffles. The remainder was run. Average stream depths varied from 19-26 cm over the period. Widths ranged from 5-14 m during the same time. Substrate ranges from fine gravel to $30 \mathrm{~cm}$ long cobbles.

All Pteronarcys $>25 \mathrm{~mm}$ body length were tagged. A meter tape placed on the shore between permanent rock cairns was the baseline used to fix the location of all insects caught.

A Smith-Root Model 11 electroshocker was used at $600 \mathrm{~V}$ DC to disturb the stoneflies out of the benthos and into a $2 \mathrm{~m}$ wide net. At each net placement, multiple passes were made until 3 successive passes showed decreasing numbers caught. Each pass included an area $3 \mathrm{~m}$ upstream of the net (i.e. $3 \mathrm{~m} \times 2 \mathrm{~m}=6 \mathrm{~m}^{2}$ ). The total time of each pass varied, but each employed $60 \mathrm{~s}$ of electricity from the shocker.

Captured stoneflies were measured across the eyes to the nearest $0.05 \mathrm{~mm}$ with a vernier caliper. Numbered tags $(\approx 2 \times 3 \mathrm{~mm})$ were attached to the insect with Super Glue. Normal time for processing from capture to release was $<20 \mathrm{~min}$.

A tag retention study on Pteronarcys scotti in Georgia showed the tags could be retained at least $6 \mathrm{mo}$. in the lab. Moreover, the glue leaves a reliable mark if the label comes off. Two exuviae were collected in the stream with tags still attached indicating that ecdysis can proceed normally.

Results From 1987

One thousand-two individuals were marked. Of these, 249 were recaptured between August and October 1987 (25\%). Size, sex, and location was recorded for each individual tagged or recaptured.

\section{Life History}

Head capsule widths indicated that Pteronarcys has a $3 \mathrm{yr}$ life cycle in Pacific Creek. Females were larger than males (maximum $56 \mathrm{~mm}$ body length, $6.0 \mathrm{~mm}$ head width). Males reached $47 \mathrm{~mm}$ ( $5.1 \mathrm{~mm}$ head width). Only 2 nd and 3 rd year males and females were tagged.

\section{Movement Patterns}

Pteronarcys were found in areas of fast, deep water with large, loosely bedded cobbles. None was ever found in a pool nor in an area with silty or fine gravel bottom. No tagged stonefly ever crossed a pool. Individuals of the same sex and size were frequently found together. 
The statistical prevalence of this phenomenon has not yet been calculated but such clumping was previously reported by Elder and Gaufin (1973).

Numbers of stoneflies tagged were similar in August, September, and October, but recapture success improved dramatically in October. This was probably due to: (1) decreasing stream volume (lack of rain), (2) increasing percentage of the population bearing tags with time, and (3) slower growth rates as winter approached (less moulting). Results show that upstream movement (given + values) overall balanced downstream movement (given - values). But the average of all movements averaged -2.71 if zero movements are removed. The absolute value of all movements averaged $9.05 \mathrm{~m}$, with zero movements deleted.

A large percentage (43\%) of the stoneflies recaptured were found at the same spot as their previous capture. It is not clear whether they had remained in that place for long periods or had returned to that place repeatedly. Tagged individuals were frequently found at the site of their original tagging several weeks (and several sampling passes) later.

Another large percentage (40\%) moved downstream and $17 \%$ moved upstream. Forty-two Pteronarcys were recaptured twice, 10 were recaptured 3 times, and 2 were recaptured 4 times. Multiple recaptures showed that an individual may move long distances in a short time and then sit in the same place for weeks before moving again.

A small number of individuals were notable for extremely rapid upstream movements. These movements ranged from $6-22 \mathrm{~m} / \mathrm{d}$ upstream (mean 10.6 $m / d, n=8)$. The farthest upstream traveler was a large female that moved $40 \mathrm{~m}$ upstream in 4 days. The fastest was another large female that covered $22 \mathrm{~m}$ upstream in a single day. Upstream movement is clear evidence of self-propelled activity. Corresponding downstream movement could be attributed to drift although it need not necessarily be.

One way ANOVA comparing the distances moved by males and females shows significant difference between the sexes $(P<.05, F=4.9, d f=212)$. The following table (based on a subset of the Pteronarcys that were clearly identifiable to age class, $n=188$ ) shows a breakdown of movements by size and sex.

The 1988 Field Season

In 1988, sampling was confined to $36,4 \mathrm{~m}^{2}$ quadrats arranged in 4 blocks of 9. Quadrats were in the "best" locations from 1987. Steel rebar was driven into the streambed to mark the quadrat corners. Most quadrats were surrounded by $1 \mathrm{~m}$ buffer zones on all sides.

Each quadrat was described by taking 35 depth measurements, 35 current velocity readings, 35 cobble lengths, and 35 cobble widths. Depths and 
Table 1. Movements by size and sex 1987.

Males 2nd yr 43 in class

3 upstream (1,5, and $15 \mathrm{~m}$ )

26 downstream

14 no movement

Males

$$
\text { 3rd yr }
$$

0 upstream

9 downstream

14 no movement

Females

$\begin{array}{cl}7 & \text { 2nd yr } \\ 76 & \text { upstream } \\ 30 & \text { downstream } \\ \text { no movement }\end{array}$

Females 3rd yr

23 upstream

19 downstream

63 in class

17 no movement

23 in class

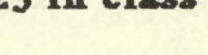

59 in cless

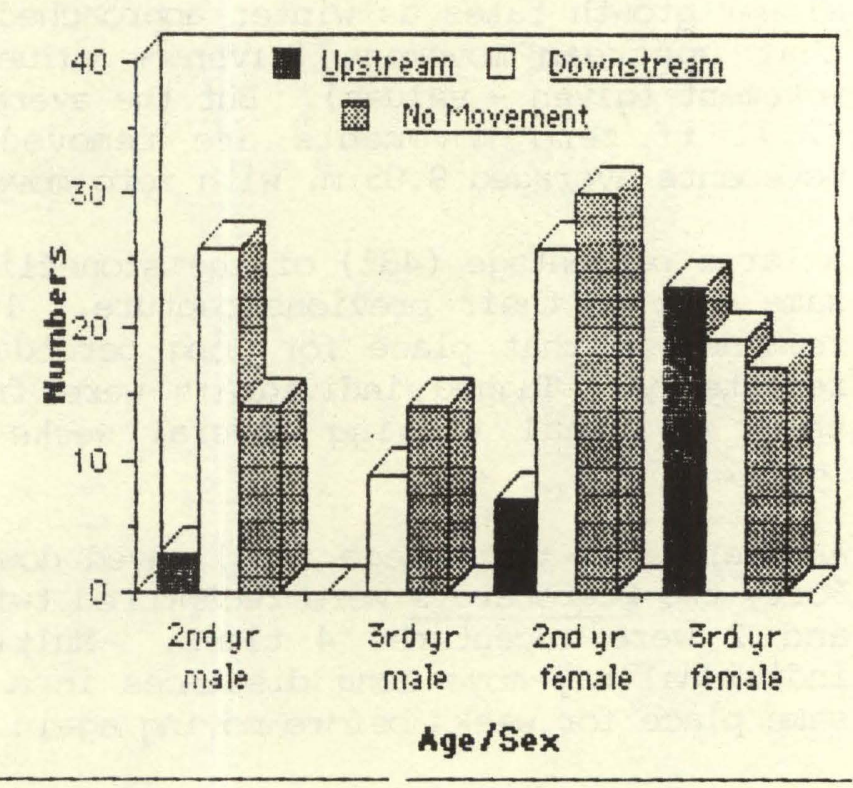


velocities were repeated twice (Aug. and Oct.). All samples were selected randomly by choosing points intersecting a 20 x 30 crn grid. The number 35 was determined by applying a Shannon-Weaver diversity index to rock sizes. Thirty five samples was the point at which the curve of new rock-size "species" reached asymptote.

The 1988 experiment manipulated food and density of stoneflies in the quadrats. The treatments chosen were added food $(+F)$, reduced food ($\mathrm{F})$, and ambient food $(\mathrm{amF})$. Density treatments were added stoneflies $(+D)$, reduced stoneflies (-D), and ambient stoneflies (amD). In amF and amD blocks, no changes were made to the quadrats. Considering both variables, there were 9 possible treatment combinations. The 9 treatments were assigned to quadrats using a random number table so each block had all 9 treatments. (The 4 blocks replicated the 9 treatments 4 times).

In $-F$ blocks, all cobbles were scrubbed with wire and nylon scrub brushes in late July. Rocks were scrubbed until all visible periphyton was removed and no "slimy" feeling remained. The $-\mathrm{F}$ blocks were then covered with $6 \mathrm{mil}$ black plastic suspended from nylon cords about $10 \mathrm{~cm}$ over the water.

In $+F$ blocks, $200 \mathrm{~g}$ of twigs and leaves (dry weight) from nearby plants (chiefly Alnus and Salix) were assembled into bundles with rubber bands. Bundles were allowed to condition in the stream in $200 \mathrm{~m}$ Nitex bags for 2 wks. After conditioning, three such bundles were added to the $+F$ quadrats every 2 wks. The 3 bundles were spaced in a triangular pattern in the center of each quadrat, weighted down with large stones. At each 2 wk replacement, old bundles were removed but the last previous bundle was allowed to remain in addition to the new bundle.

In -D blocks, all Pteronarcys found were removed, tagged, and placed in $+\mathrm{D}$ blocks.

In $+D$ blocks, stoneflies from $-D$ blocks were added. Since the number of insects found in the -D blocks varied each time sampled, the numbers added to $+D$ blocks also varied. The original intention was to add numbers and sexes in some proportion to absolute density or previous sex ratio. In practice, this proved impossible. The Pteronarcys were less abundant than in 1987 and were hard to catch. So weekly additions to +D represent a different proportion of previous density each time.

As in 1987 , sampling was done by electroshocking $60 \mathrm{~s}$ at 600 VDC. However in 1988, 6 passes were used in all cases. Using a better cathode increased capture probability; numbers per pass nearly always declined to zero within 5 passes.

Results From 1988

In 1988, 482 individuals were tagged. Of these, 211 were recaptured 
between August and November 1988 (44\%). Thirty four were caught 2 times, 3 were recaught 3 times.

Preliminary results show that movement patterns were very different in 1988. Overall densities were much lower than in 1987. Movements were much shorter with almost no long distance upstream travel. Long range downstream movements were also rare. By far the largest number of movements were 1-2 meters up/down stream.

Analysis of quadrat-use by treatment has not yet begun. In addition to the 2-way ANOVA to look at food vs density effects, physiological analyses will be conducted to see if stoneflies in $+F$ blocks are significantly different from conspecifics in nearby $-F$ blocks. Gut contents of Pteronarcys captured in each quadrat also will be analyzed.

Additional results will be submitted to the University of Wyoming as they become available. Data analysis and dissertation writing will occupy the winter and spring of 1989.

\section{Acknowledgements}

This project would not have been possible without the help of Ken Diem, Bruce Adams, and Joe Neal at the University of Wyoming/NPS Research Center. Thanks also to Bob wood, Patrick Smith, Pat Metheny and Bob cooper of Grand Teton National Park. Jim Braman was a friend of the project and allowed access to the study site through his property.

\section{Literature Cited}

Elder, J. A. and A. R. Gaufin. 1973. Notes on occurrence and distribution of Pteronarcys californica Newport (Plecoptera) within streams. Great Basin Nat. 33:218-220.

Grossman, G. D., P. B. Moyle, and J. O. Whitaker, Jr. 1982. Stochasticity in structural and functional characteristics of an Indiana stream fish assemblage: a test of community theory. Amer. Nat. 120:423-454.

Hart, D. D. 1983. The importance of competitive interactions within stream populations and communities. In: Barnes, J. R. and G. W. Minshall (eds). Stream Ecology: Plenum, NY. pp 99-136.

Knight, A. W. and A. R. Gaufin. 1963. The effect of water flow, temperature, and oxygen concentrations on the Plecoptera nymph Acroneuria pacifica Banks. Proc. Utah Acad. Sci. 40:175-184.

Peckarsky, B. L. 1979. Biological interactions as determinants of distributions of benthic invertebrates within the substrate of stony streams. Limnol. Oceanogr. 24:59-68. 